\title{
Evaluation of Rock Quality of Tunnel Wall Rock Based on Rough Set Theory and Unascertained Measurement Theory
}

\author{
Changfu Huang, ${ }^{1,2}$ Shuguang Tian $\mathbb{D}^{1},{ }^{1}$ Qun Li, ${ }^{2}$ and Jun Huang ${ }^{1}$ \\ ${ }^{1}$ China Railway 16th Bureau Group Co., Ltd., Beijing 100018, China \\ ${ }^{2}$ School of Civil and Resources Engineering, University of Science and Technology Beijing, Beijing 100083, China \\ Correspondence should be addressed to Shuguang Tian; tsg880917@gmail.com
}

Received 6 February 2018; Accepted 7 June 2018; Published 24 July 2018

Academic Editor: Anna Vila

Copyright (c) 2018 Changfu Huang et al. This is an open access article distributed under the Creative Commons Attribution License, which permits unrestricted use, distribution, and reproduction in any medium, provided the original work is properly cited.

\begin{abstract}
A method for classification of the tunnel wall rock is established based on the rough set theory and unascertained measurement theory. The saturated uniaxial compressive strength, rock mass integrity index, structural surface condition, seepage measurement of groundwater, and the angle between the hole axis and main structural surface are selected as the evaluation indexes. The problem of weight coefficients for these evaluation indexes is converted into that of significance estimating on the attributes in the rough set theory. The proposed method is verified by the wall rock data of Yuanyanghui tunnel. The results show that the proposed method has an excellent performance in good agreement with the practical situation of wall rock and is feasible to classify the wall rock. Finally, the proposed method is applied to Xihualing tunnel of Zhu-Yong Expressway. The results are basically the same as those from Delphi-ideal point method, set pair analysis method, and the actual situation, which proves that the rough set theory and unascertained measurement theory are effective for classification of the wall rock.
\end{abstract}

\section{Introduction}

Reasonable classification of the wall rock plays an important role in guiding the construction of the tunnel and is an also important basis for evaluating the stability of the wall rock and selecting suitable support. However, due to the complexity of the engineering geological conditions in the tunnel, the classification of the wall rock is always not accurate enough, leading to a certain difference with the actual rock grade. These problems result in the changes in the design during the tunnel construction and seriously affect the construction progress. Therefore, it is of great significance to develop an accurate and simple classification method for wall rock.

In the tunnel construction, the wall rock of the construction area should be classified and its quality also be evaluated. At present, there are many kinds of rock quality evaluation methods including traditional methods (RQD method [1], RMR method [2], RMi method [3, 4], etc.) and new methods (fuzzy theory [5], artificial neural networks [6,7], extension theory [8], fractal theory [9], etc.). The above methods and theory have been introduced into the study of tunnel rock classification and some achievements have been achieved.
However, each theory or method has its own characteristics and shortcomings; it cannot well serve the actual tunnel construction. Therefore, it is necessary to explore the new method of classification of wall rock.

In 1990, Wang [10] proposed the unascertained information theory, which is different from the fuzzy information [11], random information [12], and grey information [13]. On this basis, Liu and Lin et al. $[14,15]$ established the unascertained measurement evaluation model and obtained satisfactory results by using the model to evaluate the reliability of an electricity supply system. Since then, the theory and evaluation model have been widely applied in many diverse fields. Parsons and Wen [16] used unascertained measurement theory to create an evaluation method to determine the condition of cement concrete pavement. Yao [17] applied unascertained theory and blind number theory in describing the uncertainty of the mechanical system failure process to help develop appropriate design validation and verification program for reliability assessment. Zhou [18] established an UM theory of blastability of rock mass predictions on the basis of unascertained measurement theory, and the model can provide an effective and credible method for estimation the blastability 
of rock mass. An unascertained measurement model of water and mud inrush risk evaluation is established founded on unascertained measurement theory, and the results show that the evaluation results agree well with practical construction situation [19].

In 1982, Pawlak [20] proposed rough set theory, which is a mathematical tool for dealing with fuzzy and uncertain knowledge. The main idea is based on indiscernibility relations that the obtained information is used to describe indistinguishability of objects. On the basis, Pawlak and Grzymala-Busse [21, 22] et al. discussed and analyzed in greater detail in their papers. Beaubouef [23] used the model based on intuitionistic and rough set developed here is applied to databases, which provided greater management of uncertainty for databases applications in a less than certain world. Yasdi [24] utilized the method combining rough set theory and neural network to study the uncertainty and imprecise information, which improved the efficiency of classification. Zhang [8] established a relation data model about tunnel wall rock evaluation based on rough set theory and extension theory.

Although the rough set theory and unascertained measurement theory have been successfully applied in many fields, the method which combined the two theories is rarely used. The purpose of the present paper is to introduce the method combining rough set theory and unascertained measurement theory to classify the wall rock. Therefore, the remainder of this paper is organized as follows. In Section 1, the method combining rough set theory and unascertained measurement theory is presented, whose evaluation process is described in detail. In Section 2, the method is applied to the classification of the wall rock and verified with the measured samples. In Section 3, a comparison study is performed based on various evaluation methods and the classification of the wall rock for the Xihualing tunnel of Zhu-Yong Expressway in China.

\section{Rough Set Theory and Unascertained Measurement Theory}

2.1. Rough Set Theory. As a mathematical method, rough set theory is proposed to deal with incomplete and uncertain data. The main idea is based on indiscernibility relations that describe indistinguishability of objects. The theory focuses on the knowledge that can be approximated from the data [2022]. The parameters most commonly found in the rough set theory are shown below.

Set the pair $K=(U, R)$ as the knowledge base, where $U$ is called the universe, which is finite and nonempty, and $R$ is called the nonempty set of attributes. $[x]_{R}$ denotes the equivalence class of $R$ containing an element $x$ of $U . X \subseteq U$, $\underline{R} X=\left\{x \in U \mid[x]_{R} \subseteq X\right\}$, and $\bar{R} X=\left\{x \in U \mid[x]_{R} \cap X \notin\right.$ $\bar{\varnothing}\}$ are defined as the lower approximation and the upper approximation of $\mathrm{X}$, respectively.

Let $P$ and $Q$ be subsets of condition attribute $C$ and decision attribute $D$, respectively; then

$$
K=\gamma_{P}(Q)=\frac{1}{|U|} \sum_{i=1}^{m}\left|\gamma_{P}\left(Q_{i}\right)\right|
$$

where $|U|$ represents the number of elements in $U$. The dependency degree of the decision set on the condition set is the value of $K$. If $K=1, Q$ is entirely dependent on $P$. Conversely, if $K=0, Q$ is completely independent of $P$.

In the decision table, different attributes have different importance. To find out the importance of certain attributes, some attributes are removed from the decision table, and then the classification changes without these attributes are analyzed. If the corresponding classification changes greatly when an attribute is removed, then the importance of this attribute is high. Therefore, the condition attribute $C_{i}$ defines the importance of the decision attribute $D$ as

$$
\begin{aligned}
\gamma_{C-C_{i}}(D) & =\frac{1}{|U|} \sum_{i=1}^{m}\left|\gamma_{C-C_{i}}\left(D_{i}\right)\right| \\
\sigma_{C D}\left(C_{i}\right) & =\gamma_{C}(D)-\gamma_{C-C i}(D)
\end{aligned}
$$

where $\gamma_{C}(D)$ is called the dependency degree.

When calculating the weights of evaluation indexes, the evaluation indexes are used as the condition attribute set, and the decision results are taken as the decision attribute set. The dependency degree of the decision set on the condition set is used to determine the weights. The main procedure is as follows.

(1) Construction of initial decision table.

(2) Samples screening: the screening principles are as follows. (1) If the sample information and evaluation system are contradictory, then the sample is removed. (2) If the condition attributes of multiple samples are the same but the decision attributes are different, then the samples with good compatibility can be retained. (3) If the condition attributes and decision attributes of different samples are the same, the samples can be merged to retain one.

(3) Reduction of the evaluation indexes: it is to remove irrelevant and redundant knowledge with maintaining the classification ability of the knowledge base and to obtain the optimal condition attributes.

(4) Construction for optimal attribute of decision table and the weight $\omega_{i}$ can be calculated by (3).

$$
\omega_{i}=\frac{\gamma_{C}(D)-\gamma_{C-C_{i}}(D)}{\sum_{i=1}^{m}\left[\gamma_{C}(D)-\gamma_{C-C_{i}}(D)\right]}
$$

2.2. Unascertained Measurement Theory. Since the concept of the unascertained information is proposed, much work has been done by many scholars, which makes the unascertained information a systematic theory and method [10, 14]. The theory is used to describe the incomplete information and refers to the decision-making-demanded information. The parameters most commonly found in the unascertained measurement theory are briefly discussed below.

(1) Unascertained Set. Unascertained set is a collection of all unascertained numbers and plays an important role in the study of unascertained mathematical theory, written $I_{[0,1]}=$ $\{\{[a, b], F(x)\}|a \geq 0, a \leq b \leq 1|\}$. Suppose that $N$ is an unascertained subset of discourse domain $U$, and $N$ is used to characterize the mapping of a membership function. The 
mapping relationship can be written as $\mu: U \longrightarrow I_{[0,1]}, u \longrightarrow$ $\mu(u) \in I_{[0,1]}, u \in U, \mu(u)$ is called the membership degree of $u$ to $N$, written $N_{\mu(u)}$.

(2) Measurable Space. Measurable space is a space composed of the property domain and its topology on the domain, written $(F, E)$. Suppose that $\left\{F_{1}, F_{2}, F_{3}, \cdots\right\}$ is a division of $F$, and let

$$
\begin{aligned}
E & =\left\{E_{i} \mid E_{i}=\bigcup_{j=1}^{i} F_{j}, F_{j} \in\left\{\varnothing, F_{1}, F_{2}, \cdots, F_{k}\right\}, 1 \leq i\right. \\
& \leq k\}
\end{aligned}
$$

where $E$ is the topology of $F$, and $F$ is the property domain on $U$. $F$ satisfies $F_{i} \cap F_{j}=\varnothing, i=j$ and $\bigcup_{i=1} F_{i}=F$.

(3) Unascertained Measurement. When $u \in U, A \in E$, the existence mapping $u$ makes $\mu_{A}(u)$ satisfy (5)-(7).

$$
\begin{aligned}
0 & \leq \mu_{A}(u) \leq 1, \quad \forall u \in U, A \in E \\
\mu_{F}(U) & =1 \\
\mu_{\bigcup_{i} A_{i}}(u) & =\sum_{i} \mu_{A_{i}}(u), \quad A_{i} \in E, A_{i} \cap A_{j}=\varnothing(i \neq j)
\end{aligned}
$$

where $\mu_{A}(u)$ is called unascertained measurement in the measurable space.

(4) Unascertained Measurement of Single Index. Set $x_{1}$, $x_{2}, \cdots, x_{n}$ as $n$ evaluation objects of the pending evaluation, and the evaluation object set is $X=\left\{x_{1}, x_{2}, \cdots, x_{n}\right\}$. Each evaluation object $x_{i}(i=1,2, \ldots, n)$ has $m$ evaluation indexes $I_{1}, I_{2}, \cdots, I_{m}$ and $I=\left\{I_{1}, I_{2}, \cdots, I_{m}\right\}$, which is the evaluation index set. Then $x_{i j}$ is expressed as a $m$ dimensional vector $x_{i}=$ $\left\{x_{i 1}, x_{i 2}, \cdots, x_{i m}\right\}$. Set $c_{k}(k=1,2, \ldots, p)$ as the $k$-th evaluation grade, and the grade of the $k$-th is superior to $(k+1)$-th, which is denoted as $c_{k}>c_{k+1}$. If $\left\{c_{1}, c_{2}, \cdots, c_{p}\right\}$ satisfies $c_{1}>c_{2}>$ $\cdots>c_{p}$, then $\left\{c_{1}, c_{2}, \cdots, c_{p}\right\}$ is called ordinal classification of the evaluation index set $U$.

Let $\mu_{i j k}=\mu\left(x_{i j} \in c_{k}\right)$ to express the degree that $x_{i j}$ belongs to $k$-th evaluation grade of $c_{k}$, and $\mu$ satisfies the flowing conditions:

$$
\begin{gathered}
0 \leq \mu\left(x_{i j} \in c_{k}\right) \leq 1 \\
(i=1,2, \cdots, n, j=1,2, \cdots, m, k=1,2, \cdots, p) \\
\mu\left(x_{i j} \in U\right)=1 \\
\quad(i=1,2, \cdots, n, j=1,2, \cdots, m) \\
\mu\left(x_{i j} \in \bigcup_{l=1}^{k} c_{l}\right)=\sum_{l=1}^{k} \mu\left(x_{i j} \in c_{l}\right) \quad(k=1,2, \cdots, p)
\end{gathered}
$$

where (8)-(10) are, respectively, called "nonnegative boundedness", "normalization," and "additivity" of $\mu$ in the evaluation set.

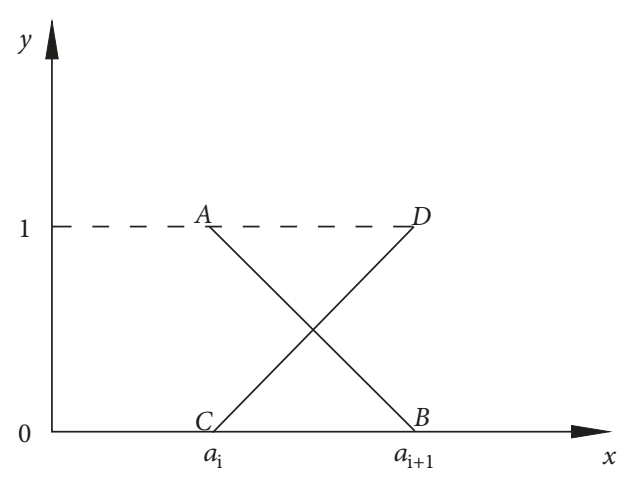

FIGURE 1: Unascertained measurement function graph of straightline type.

Then $\mu$ is called unascertained measurement and the matrix $\mu_{i j k}$ can be written as

$$
\left(\mu_{i j k}\right)_{m \times p}=\left[\begin{array}{cccc}
\mu_{i 11} & \mu_{i 12} & \cdots & \mu_{i 1 p} \\
\mu_{i 21} & \mu_{i 22} & \cdots & \mu_{i 2 p} \\
\vdots & \vdots & \ddots & \vdots \\
\mu_{i m 1} & \mu_{i m 2} & \cdots & \mu_{i m p}
\end{array}\right]
$$

When "uncertainty" is described by the unascertained set, the key is to construct a rational function of the single index measurement. Normally, there are four common kinds for the construction type of single index function, such as straightline type, para-curve type, sine curve type, and exponential curve type. Among the types, the straight-line type is the most widely used and simplest unascertained measurement function, so the function of the straight-line type is adopted to calculate the parameters in the present study. The function graph of straight-line type is shown in Figure 1.

The expression for the corresponding index function in the interval $\left[a_{i}, a_{i+1}\right]$ is

$$
\begin{gathered}
y_{i}(x)= \begin{cases}\frac{-x}{a_{i+1}-a_{i}}+\frac{a_{i+1}}{a_{i+1}-a_{i}}, & a_{i}<x \leq a_{i+1} \\
0, & x>a_{i+1}\end{cases} \\
y_{i+1}(x)= \begin{cases}0, & x \leq a_{i} \\
\frac{x}{a_{i+1}-a_{i}}-\frac{a_{i}}{a_{i+1}-a_{i}}, & a_{i}<x \leq a_{i+1}\end{cases}
\end{gathered}
$$

(5) Multi-Index Unascertained Measurement. The dependence of unascertained measurement theory on each evaluation index is different. Suppose that the evaluation index weight $w_{i j}\left(0 \leq w_{i j} \leq 1, \sum_{j=1}^{m} w_{i j}=1\right)$ is the relative important extent of evaluation index $I_{j}$ compared with other indexes, which reflects the importance of single index in the whole evaluation index set. Then $w_{i j}$ is called the weight of $I_{j}$.

Parameter $\mu_{i j k}$ is denoted as the degree of the assessment object belonging to the $k$-th evaluation grade and defined as

$$
\mu_{i k}=\sum_{j=1}^{m} w_{i j} \mu_{i j k}, \quad(i=1,2, \cdots, n ; k=1,2, \cdots, p)
$$


TABLE 1: Classification criteria of the structural surface.

\begin{tabular}{ll}
\hline Structural surface condition & Value \\
\hline Thickness of soft rock strata $>5 \mathrm{~mm}$, joint width $>5 \mathrm{~mm}$ and joint is continuous & $0 \sim 2$ \\
Joint surface is smooth or thickness soft rock strata $<5 \mathrm{~mm}$, joint opening width is $1 \sim 5 \mathrm{~mm}$ and joint is continuous & $2 \sim 4$ \\
Joint surface is a little rough, joint width $<1 \mathrm{~mm}$ and rock of joint surface is weak & $4 \sim 7$ \\
Joint surface is a little rough, joint width $<1 \mathrm{~mm}$ and rock of joint surface is hard & $7 \sim 9$ \\
Joint surface is very rough, joint width is zero, rock of joint surface is hard, the joint surface is discontinuous & $9 \sim 10$ \\
\hline
\end{tabular}

TABLE 2: Classification criteria of the wall rock quality.

\begin{tabular}{lccccc}
\hline Grade & $\sigma_{c} / \mathrm{MPa}$ & $K_{\mathrm{V}}$ & $S_{\mathrm{S}}$ & $W /\left[\mathrm{L} \cdot(\mathrm{min} \cdot 10 \mathrm{~m})^{-1}\right]$ \\
\hline I & $300 \sim 250$ & $1.0 \sim 0.75$ & $10 \sim 9$ & $0 \sim 5$ & $0 /^{\circ}$ \\
II & $250 \sim 100$ & $0.75 \sim 0.55$ & $9 \sim 7$ & $5 \sim 10$ & $90 \sim 80$ \\
III & $100 \sim 50$ & $0.55 \sim 0.35$ & $7 \sim 4$ & $10 \sim 25$ & $80 \sim 70$ \\
IV & $50 \sim 25$ & $0.35 \sim 0.15$ & $4 \sim 2$ & $25 \sim 125$ & $70 \sim 30$ \\
V & $25 \sim 1$ & $0.15 \sim 0$ & $2 \sim 0$ & $125 \sim 300$ & $30 \sim 10$ \\
\hline
\end{tabular}

where $\mu_{i k}$ satisfies $0 \leq \mu_{i k} \leq 1$ and $\sum_{k=1}^{p} \mu_{i k}=1 \cdot \mu_{i k}=$ $\left(\mu_{i 1}, \mu_{i 2}, \cdots, \mu_{i p}\right)$ is called multi-index measurement evaluation vector of the evaluation object $x_{i}$.

(6) Evaluation Criterion. It is necessary to adopt the credible degree recognition criteria to analyze the evaluation object. $\lambda$ is set as credible degree, whose range of values is $0.5 \leq \lambda \leq 1$. If the evaluation index set $U$ satisfies $c_{1}>c_{2}>\cdots>c_{p}$, let

$$
k_{0}=\min \left\{k: \sum_{l=1}^{k} \mu_{i l} \geq \lambda, k=1,2, \cdots, p\right\}
$$

Based on the above six steps, it is judged that evaluation object $x_{i}$ belongs to the $k_{0}$-th evaluation grade.

2.3. Evaluation Process of RS Theory and UM Theory. The evaluation process of rough set theory and unascertained measurement theory is depicted in Figure 2. Firstly, the evaluation system is constructed based on the rough set theory and unascertained measurement theory. Secondly, by using the measured data of the wall rock samples, the single index measurement function and measurement evaluation matrix are established. Then, according to (3), the weights of each evaluation index are obtained by significance estimating on the attributes in the rough set theory. Finally, the multiindex measurement evaluation vector is calculated, and the wall rock grade is identified according to the credible degree recognition criteria.

\section{RS Theory and UM Theory for Quality Evaluation of Tunnel Wall Rock}

3.1. Evaluation Index System of Tunnel Wall Rock Quality. The geological conditions of tunnel engineering are complex and changeable, which is influenced by many factors. The wall rock quality depends on not only the physical and mechanical properties of the wall rock, but also the external engineering geological factors such as groundwater. On the basis of relevant research results $[8,9,25,26]$, a comprehensive

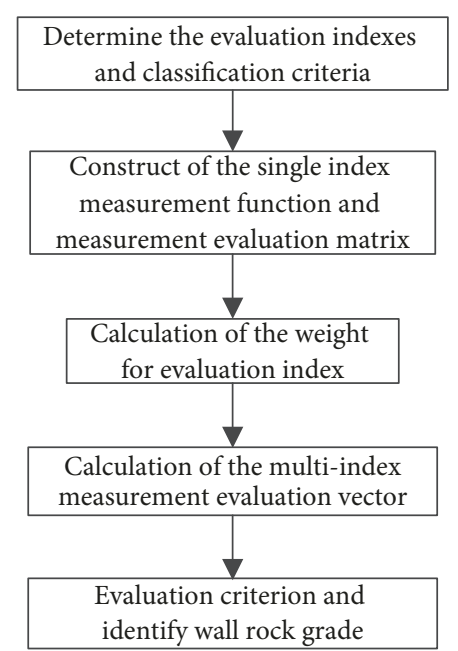

FIGURE 2: The evaluation process of RS theory and UM theory.

evaluation index system is established, which takes saturated uniaxial compressive strength $\sigma_{c}$, rock mass integrity index $K_{\mathrm{V}}$, structural surface condition $S_{\mathrm{S}}$, seepage measurement of groundwater $W$, and the angle between the hole axis and main structural surface $\theta$ as the evaluation indexes. The wall rock grade is divided into five grades, and its evaluation index set is $\left\{C_{1}, C_{2}, C_{3}, C_{4}, C_{5}\right\}=\{I, I I, I I I, I V, V\}$. Since structural surface condition is a qualitative index, it is converted into semiquantitative index by assignment method whose corresponding assignment is listed in Table 1. The classification criteria of wall rock quality are shown in Table 2.

In this paper, 25 measured wall rock data $\left(x_{1}, x_{2}, \ldots\right.$, $x_{25}$ ) are chosen as the samples to test the feasibility of rock classification based on rough set theory and unascertained measurement theory. The measured wall rock samples belong to Yuanyanghui tunnel, which is located in Shanyin-Pinglu section of Rong-Wu Expressway and is a separated tunnel with four lanes. The evaluation method is applied to evaluate 
TABLE 3: Raw data of the rock samples.

\begin{tabular}{|c|c|c|c|c|c|c|}
\hline Sample & $\sigma_{c} / \mathrm{MPa}$ & $K_{\mathrm{V}}$ & $S_{S}$ & $W /\left[\mathrm{L} \cdot(\min \cdot 10 \mathrm{~m})^{-1}\right]$ & $\theta /^{\circ}$ & Actual rock grade \\
\hline 1 & 62 & 0.35 & 1.5 & 5.3 & 10 & IV \\
\hline 2 & 72 & 0.19 & 9.0 & 7.4 & 87 & IV \\
\hline 3 & 65 & 0.32 & 9.3 & 11 & 17 & III \\
\hline 4 & 61 & 0.34 & 2.5 & 5.2 & 46 & IV \\
\hline 5 & 73 & 0.77 & 9.1 & 7.8 & 63 & II \\
\hline 6 & 37 & 0.42 & 6.7 & 7.5 & 77 & IV \\
\hline 7 & 58 & 0.28 & 5.8 & 2.0 & 42 & III \\
\hline 8 & 61 & 0.35 & 9.0 & 7.1 & 25 & III \\
\hline 9 & 65 & 0.34 & 2.5 & 4.6 & 67 & III \\
\hline 10 & 52 & 0.32 & 9.6 & 6.0 & 86 & III \\
\hline 11 & 67 & 0.27 & 8.2 & 0 & 58 & III \\
\hline 12 & 63 & 0.33 & 9.6 & 8.7 & 24 & III \\
\hline 13 & 28 & 0.20 & 7.5 & 5.8 & 65 & IV \\
\hline 14 & 58 & 0.28 & 9.5 & 15.9 & 16 & III \\
\hline 15 & 36 & 0.25 & 3.8 & 5.9 & 83 & IV \\
\hline 16 & 28 & 0.28 & 3.5 & 6.2 & 82 & IV \\
\hline 17 & 82 & 0.24 & 9.3 & 7.4 & 19 & III \\
\hline 18 & 34 & 0.31 & 4.0 & 0 & 7 & IV \\
\hline 19 & 26 & 0.32 & 3.3 & 0 & 14 & IV \\
\hline 20 & 27 & 0.58 & 1.5 & 11.4 & 36 & III \\
\hline 21 & 46 & 0.21 & 2.5 & 8.3 & 82 & IV \\
\hline 22 & 33 & 0.42 & 5.7 & 5.2 & 82 & III \\
\hline 23 & 12 & 0.17 & 1.5 & 5.1 & 67 & $\mathrm{~V}$ \\
\hline 24 & 6 & 0.21 & 1.7 & 6.4 & 53 & $\mathrm{~V}$ \\
\hline 25 & 7 & 0.13 & 3.3 & 5.9 & 46 & $\mathrm{~V}$ \\
\hline
\end{tabular}

the wall rock grade. The raw data of the wall rock samples are listed in Table 3.

\subsection{Construction of the Single Index Measurement Function.} On the basis of the straight-line type function and classification criteria of structural surface (Table 1), the single index measurement functions are constructed to get the unascertained measurement value of the evaluation index. According to the classification criteria in Table 2 and taking sample 1 as an example, the single index measurement function of saturated uniaxial compressive strength, rock mass integrity index, structural surface condition, groundwater seepage, the angle between the hole axis, and main structural surface are shown in Figure 3.

The values of evaluation indexes for sample 1 in Table 3 are substituted into the corresponding unascertained measurement functions in Figure 2. Thus, the measurement evaluation matrix of single index can be obtained in

$$
\left(\mu_{1 j k}\right)_{5 \times 5}=\left[\begin{array}{ccccc}
0 & 0 & 0.65 & 0.35 & 0 \\
0 & 0 & 0.5 & 0.5 & 0 \\
0 & 0 & 0 & 0 & 1 \\
0.56 & 0.44 & 0 & 0 & 0 \\
0 & 0 & 0 & 0 & 1
\end{array}\right]
$$

3.3. Calculation of the Weight for Evaluation Index. (1) The initial decision table is constructed according to the evaluation criteria of the wall rock quality and the raw data of the rock samples. The evaluation indexes and actual rock grade are taken as the condition attribute set and decision attribute set, respectively. The initial decision table for evaluation indexes of wall rock quality is established in Table 4.

(2) The samples in the initial decision table are screened according to the screening principles. According to the principle (1), $x_{6}$ is removed. Because the decision attributes of $x_{2}$ and $x_{10}$ are different, let $x_{10}$ be retained based on the principle (2). In the initial decision table, $x_{3}=x_{14}, x_{8}=x_{12}=x_{17}$, $x_{15}=x_{21}, x_{23}=x_{24}$, which mean that the condition attributes and decision attributes of multiple samples are the same, so $x_{3}, x_{8}, x_{15}$, and $x_{23}$ are retained according to the principle (3).

(3) After the attributes of the decision table are reduced, the redundancy condition attribute is not found. That is to say, saturated uniaxial compressive strength, rock mass integrity index, structural surface condition, groundwater seepage, and the angle between the hole axis and the main structural surface are core attributes.

After data processing, the optimal attribute of decision table for evaluation indexes of wall rock quality is obtained. The optimal attribute of decision table is 18 rows and 6 columns, which is listed in Table 5.

(4) Calculation of the weight for each evaluation index: firstly, according to (1), $K=\gamma_{c}(D)=0.9$ can be obtained by 


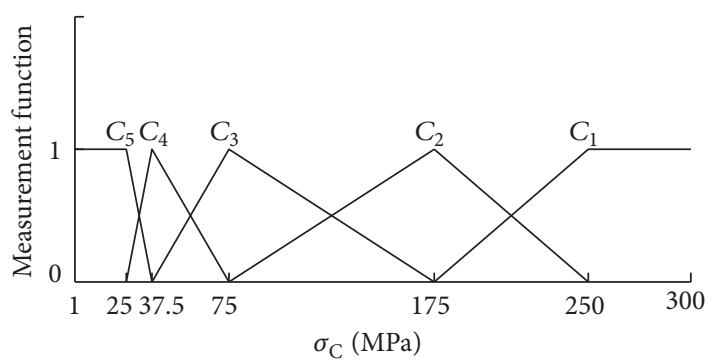

(a)

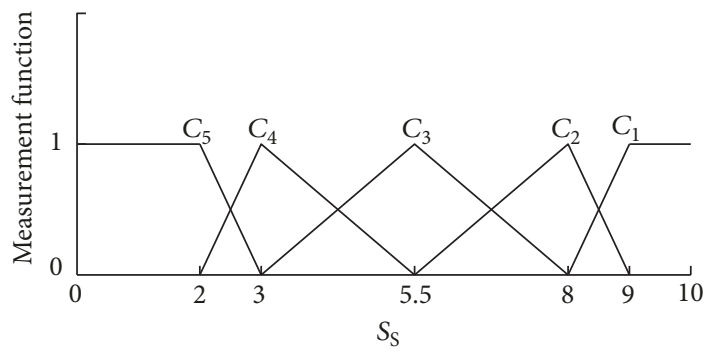

(c)

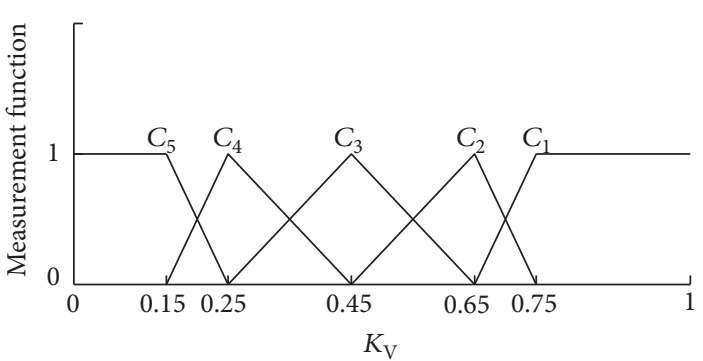

(b)

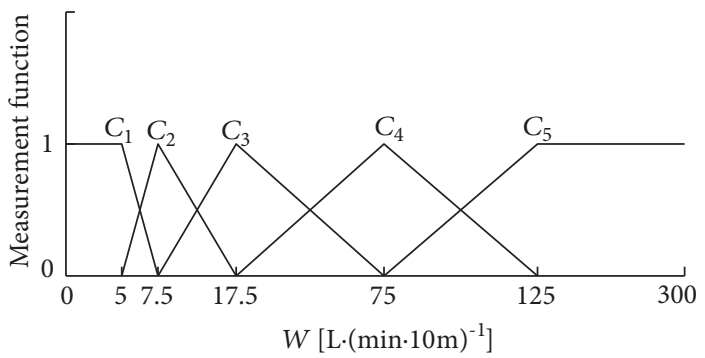

(d)

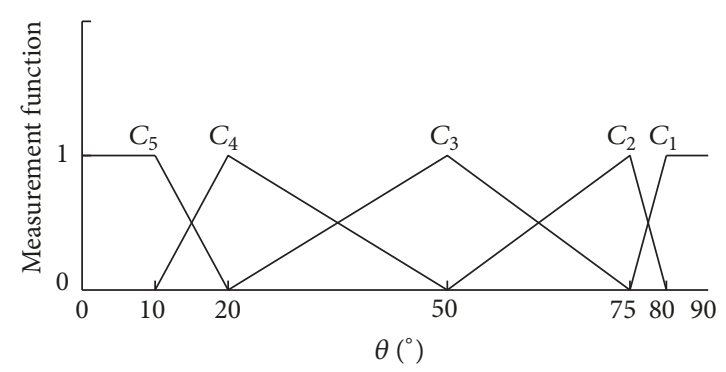

(e)

FIgURE 3: Unascertained measurement function of evaluation indexes.

calculating the optimal attribute of decision table, which indicates that the decision attribute $D$ depends on the condition attribute $C$. Secondly, for each evaluation index, the dependency degree $\gamma_{C_{-} C_{i}}(D)$ of the decision attribute $D$ on the condition attribute $C-C_{i}$ can be obtained by $(2) \cdot \gamma_{C-C_{i}}(D)$ of the evaluation indexes $\sigma_{c}, K_{\mathrm{V}}, S_{\mathrm{S}}, W$, and $\theta$ are $0.658,0.718$, $0.718,0.823$, and 0.833 , respectively. Thirdly, the importance of the evaluation indexes in the indexes set can be got based on (2). Then, $\sigma_{C D}\left(C_{i}\right)$ of the evaluation indexes $\sigma_{c}, K_{\mathrm{V}}, S_{\mathrm{S}}$, $W$, and $\theta$ are $0.242,0.182,0.182,0.077$, and 0.067 , respectively. Finally, (2) and (3) yield the weights of the evaluation index and the weight $\omega_{i}=(0.242 /(0.242+0.182+0.182+0.077+$ $0.067))=0.323$ for evaluation index $\sigma_{c}$. Similarly, the weights of $K_{\mathrm{V}}, S_{\mathrm{S}}, W$, and $\theta$ are $0.243,0.243,0.102$, and 0.089 .

\subsection{Calculation of the Multi-Index Measurement Evaluation} Vector. For sample 1, the weights are obtained on the above calculation. The multi-index measurement evaluation vector of sample 1 can be obtained according to the single index evaluation matrix (12) and (13), which is $\{0.057,0.045,0.331$, $0.235,0.332\}$. Similarly, the multi-index measurement evaluation vector of other samples can also be obtained.

3.5. Evaluation Criterion. Credible degree recognition is performed using (14) and multi-index measurement evaluation vector of sample 1 . Here, $\lambda$ is set as $0.6, k_{0}=0.057+0.045+$ $0.331+0.235=0.668>\lambda=0.6$. Therefore, the wall rock grade of the sample 1 belongs to grade IV. Similarly, the rock grade of other samples can be obtained, and the evaluation results are listed in Table 6.

From the analysis of evaluation results, the results of the wall rock quality using the evaluation method based on rough set theory and unascertained measurement theory are basically the same as these of the actual rock grade. However, the rock grade of sample 9 is classified inaccurately as grade IV. The reason may be that the actual rock grade is between grade III and grade IV. So the evaluation method determines the grade of sample 9 as a low-grade wall rock, which is allowed from the view of construction safety. Thus, the evaluation method of wall rock quality based on rough set theory and unascertained measurement theory has a high accuracy, which is feasible for determination of wall rock quality.

\section{Engineering Application}

Reasonable classification of the wall rock plays an important role in guiding the design and construction of the tunnel and can serve as an important basis for evaluating the stability of the wall rock. To test the accuracy of the rock quality 
TABLE 4: Initial decision table for evaluation indexes of wall rock quality.

\begin{tabular}{llccccc}
\hline \multirow{2}{*}{ Sample } & \multicolumn{2}{c}{ Rock grade determined by individual evaluation indexes } & \multicolumn{2}{c}{ Actual rock } \\
\hline 1 & $\sigma_{c}$ & $K_{V}$ & $S_{S}$ & $W$ & grade \\
2 & III & IV & V & II & V & IV \\
3 & III & IV & I & II & I & IV \\
4 & III & IV & I & III & IV & III \\
5 & III & IV & IV & II & IV \\
6 & III & I & I & II & III & II \\
7 & IV & III & III & II & IV \\
8 & III & IV & III & I & III & III \\
9 & III & IV & I & II & IV & III \\
10 & III & IV & IV & I & III & III \\
11 & III & IV & I & II & I & III \\
12 & III & IV & II & I & III & III \\
13 & III & IV & I & II & III & IV \\
14 & IV & IV & II & II & III \\
15 & III & IV & I & III & I & IV \\
16 & IV & IV & IV & II & V & IV \\
17 & IV & IV & II & II & IV & III \\
18 & III & IV & I & II & V & IV \\
19 & IV & IV & IV & I & IV & IV \\
20 & IV & IV & IV & I & II & III \\
21 & III & II & V & II & I & IV \\
22 & IV & IV & IV & II & III \\
23 & IV & III & III & V & II & V \\
24 & V & IV & IV & IV & II & V \\
\hline
\end{tabular}

evaluation method based on the rough set theory and unascertained measurement theory, the measured samples of the wall rock in the Xihualing tunnel are taken as samples for analysis. The tunnel is located in Jinhua section of ZhuYong Expressway, which is a separated tunnel with four lanes. Additionally, the rock quality evaluation results are based on each of the following three methods: Delphi-ideal point method [25], set pair analysis method [26], rough set theory, and unascertained measurement theory. The evaluation results of the above three methods and the actual grade can be found in Table 7 .

First, the multi-index unascertained measurement of each tunnel is calculated based on rough set theory and unascertained measurement theory, the wall rock grade is determined according to the credible degree recognition. The evaluation results are consistent with those of Delphiideal point method, set pair analysis method, and the actual condition.

From the classification of tunnel collapse risk in Table 7, the risk grade of the mileage (K107+776 806 and K107+806 836 ) in the right tunnel of the Xihualing tunnel is grade III, which means that the tunnel may occasionally collapse. Hence, the problems should be taken into account during construction. The risk grade of the mileage $(\mathrm{K} 107+776 \sim$
806 and K107+806 836) in the left tunnel is grade IV, which means that the possibility of the tunnel collapse is greater. The evaluation results coincide with the actual wall rock conditions encountered during construction. During the tunnel construction, it was found that the wall rock exposed by the tunnel was broken and the rock quality was poor. Thus, the actions such as strengthening forepoling and shortening the excavation footage are taken to avoid the occurrence of the tunnel excavation accidents.

\section{Conclusions}

In this paper, a method combining the rough set theory and unascertained measurement theory is applied to the classification of tunnel wall rock for the first time. According to the rough set theory, the weights of evaluation indexes are obtained by significance estimating on the attributes. Thus, a method for classification of wall rock of tunnels is established based on the basic principles of unascertained measurement theory. The method is used to classify the measured wall rock samples, and the evaluation results are compared with the actual wall rock grade. It is proved that the method is feasible for determination of wall rock quality. 
TABLE 5: Optimal attribute of decision table for evaluation indexes of wall rock quality.

\begin{tabular}{|c|c|c|c|c|c|c|}
\hline \multirow{2}{*}{ Sample } & \multicolumn{4}{|c|}{ Rock grade determined by individual evaluation indexes } & & \multirow{2}{*}{$\begin{array}{l}\text { Actual rock } \\
\text { grade }\end{array}$} \\
\hline & $\sigma_{c}$ & $K_{\mathrm{V}}$ & $S_{\mathrm{S}}$ & $W$ & $\theta$ & \\
\hline 1 & III & IV & $\mathrm{V}$ & II & $\mathrm{V}$ & IV \\
\hline 3 & III & IV & $\mathrm{I}$ & III & IV & III \\
\hline 4 & III & IV & IV & II & III & IV \\
\hline 5 & III & I & I & II & III & II \\
\hline 7 & III & IV & III & I & III & III \\
\hline 8 & III & IV & I & II & IV & III \\
\hline 9 & III & IV & IV & I & III & III \\
\hline 10 & III & IV & I & II & I & III \\
\hline 11 & III & IV & II & I & III & III \\
\hline 13 & IV & IV & II & II & III & IV \\
\hline 15 & IV & IV & IV & II & I & IV \\
\hline 16 & IV & IV & II & II & $\mathrm{V}$ & IV \\
\hline 18 & IV & IV & IV & I & $\mathrm{V}$ & IV \\
\hline 19 & IV & IV & IV & I & IV & IV \\
\hline 20 & IV & II & $\mathrm{V}$ & III & III & III \\
\hline 22 & IV & III & III & II & I & III \\
\hline 23 & $\mathrm{~V}$ & IV & $\mathrm{V}$ & II & II & $\mathrm{V}$ \\
\hline 25 & $\mathrm{~V}$ & $\mathrm{~V}$ & IV & II & III & $\mathrm{V}$ \\
\hline
\end{tabular}

TABLE 6: Evaluation results of wall rock quality.

\begin{tabular}{|c|c|c|c|c|c|c|c|}
\hline \multirow{2}{*}{ Sample } & \multicolumn{5}{|c|}{ Comprehensive unascertained measurement } & \multicolumn{2}{|c|}{ Evaluation results } \\
\hline & $C_{1}$ & $\mathrm{C}_{2}$ & $\mathrm{C}_{3}$ & $\mathrm{C}_{4}$ & $\mathrm{C}_{5}$ & RS-UM & Actual grade \\
\hline 1 & 0.057 & 0.045 & 0.331 & 0.235 & 0.332 & IV & IV \\
\hline 3 & 0.243 & 0.066 & 0.357 & 0.307 & 0.027 & III & III \\
\hline 4 & 0.094 & 0.008 & 0.390 & 0.386 & 0.122 & IV & IV \\
\hline 5 & 0.486 & 0.145 & 0.353 & 0.016 & 0 & II & II \\
\hline 7 & 0.102 & 0.049 & 0.466 & 0.383 & 0 & III & III \\
\hline 8 & 0.259 & 0.086 & 0.340 & 0.315 & 0 & III & III \\
\hline 9 & 0.102 & 0.061 & 0.374 & 0.342 & 0.122 & IV & III \\
\hline 10 & 0.373 & 0.061 & 0.355 & 0.211 & 0 & III & III \\
\hline 11 & 0.151 & 0.223 & 0.340 & 0.287 & 0 & III & III \\
\hline 13 & 0.069 & 0.280 & 0.084 & 0.199 & 0.367 & IV & IV \\
\hline 15 & 0.154 & 0.037 & 0.078 & 0.692 & 0.039 & IV & IV \\
\hline 16 & 0.142 & 0.049 & 0.085 & 0.478 & 0.245 & IV & IV \\
\hline 18 & 0.102 & 0 & 0.170 & 0.548 & 0.179 & IV & IV \\
\hline 19 & 0.102 & 0 & 0.187 & 0.360 & 0.351 & IV & IV \\
\hline 20 & 0.243 & 0.220 & 0.172 & 0.094 & 0.271 & III & III \\
\hline 22 & 0.183 & 0.028 & 0.430 & 0.243 & 0.116 & III & III \\
\hline 23 & 0.098 & 0.065 & 0.028 & 0.292 & 0.517 & $\mathrm{~V}$ & $\mathrm{~V}$ \\
\hline 25 & 0.065 & 0.037 & 0.041 & 0.291 & 0.566 & $\mathrm{~V}$ & $\mathrm{~V}$ \\
\hline
\end{tabular}

Note: RS-UM is the evaluation method based on rough set theory and unascertained measurement theory. 
TABLE 7: Evaluation results of wall rock classification.

\begin{tabular}{|c|c|c|c|c|c|c|c|c|c|}
\hline \multirow{2}{*}{$\begin{array}{l}\text { Tunnel } \\
\text { mileage }\end{array}$} & \multicolumn{5}{|c|}{ Comprehensive unascertained measurement } & \multicolumn{4}{|c|}{ Evaluation results } \\
\hline & $C_{1}$ & $C_{2}$ & $C_{3}$ & $C_{4}$ & $C_{5}$ & RS-UM & SPA & D-IP & $\begin{array}{l}\text { Actual } \\
\text { grade }\end{array}$ \\
\hline $\begin{array}{l}\text { Left tunnel, } \\
\text { K106+760 } \\
790\end{array}$ & 0 & 0.056 & 0.355 & 0.589 & 0 & IV & IV & IV & IV \\
\hline $\begin{array}{l}\text { Left tunnel, } \\
\text { K106+790 } \\
820\end{array}$ & 0 & 0 & 0.333 & 0.546 & 0.121 & IV & IV & IV & IV \\
\hline $\begin{array}{l}\text { Right tunnel, } \\
\text { K107+776 } \\
806\end{array}$ & 0.102 & 0.219 & 0.519 & 0.160 & 0 & III & III & III & III \\
\hline $\begin{array}{l}\text { Right tunnel, } \\
\text { K107+806 } \\
836\end{array}$ & 0.248 & 0.106 & 0.560 & 0.087 & 0 & III & III & III & III \\
\hline
\end{tabular}

Note: RS-UM is the evaluation method based on rough set theory and unascertained measurement theory, SPA is set pair analysis method, and D-IP is Delphiideal point method.

In addition, the method based on the rough set theory and unascertained measurement theory is applied to an engineering case study. The evaluation results are consistent with those of Delphi-ideal point method, set pair analysis method, and the actual condition. It provides the basis and guidance for the construction of the tunnel. Meanwhile, it is proved that the method has a good applicability and gives references for the classification of wall rock in other similar tunnel projects.

\section{Data Availability}

The data used to support the findings of this study are available from the corresponding author upon request

\section{Conflicts of Interest}

The authors declare that there are no conflicts of interest regarding the publication of this paper.

\section{Acknowledgments}

This work was supported by the National Natural Science Foundation of China (51374032), the Beijing Training Project for the Leading Talents in S\&T (Z151100000315014), and the Fundamental Research Funds for the Central Universities (FRF-TP-16-021A3).

\section{References}

[1] D. U. Deere, “Technical description of rock cores for engineering purposes," Tech. Rep., University of Illinois, 1962.

[2] Z. Bieniawski, "Engineering classification of jointed rock masses. discussions of paper by Z.T. Bieniawski, trans. s. afr. instn. civ. engrs. v15, n12, Dec. 1973, and authors reply," International Journal of Rock Mechanics and Mining Sciences \& Geomechanics Abstracts, vol. 11, no. 12, p. 244, 1974.

[3] A. Palmstrøm, "Characterizing rock masses by the RMi for Use in Practical Rock Engineering: Part 1: the development of the
Rock Mass index (RMi)," Tunnelling and Underground Space Technology, vol. 11, no. 2, pp. 175-188, 1996.

[4] A. Palmstrøm, "Characterizing rock masses by the RMi for use in practical rock engineering, Part 2: some practical applications of the rock mass index (RMi)," Tunnelling and Underground Space Technology, vol. 11, no. 3, pp. 287-303, 1996.

[5] J. L. Rangel, U. Iturrarán-Viveros, A. G. Ayala, and F. Cervantes, "Tunnel stability analysis during construction using a neurofuzzy system," International Journal for Numerical and Analytical Methods in Geomechanics, vol. 29, no. 15, pp. 1433-1456, 2005.

[6] A. T. C. Goh and W. Zhang, "Reliability assessment of stability of underground rock caverns," International Journal of Rock Mechanics and Mining Sciences, vol. 55, pp. 157-163, 2012.

[7] A. Alimoradi, A. Moradzadeh, R. Naderi, M. Z. Salehi, and A. Etemadi, "Prediction of geological hazardous zones in front of a tunnel face using TSP-203 and artificial neural networks," Tunnelling and Underground Space Technology, vol. 23, no. 6, pp. 711-717, 2008.

[8] X. Z. Huang and C. X. She, "Research on methods of wall rock masses stability classification based on extension theory," Rock and Soil Mechanics, Rock and Soil Mechanics, vol. 27, no. 10, pp. 1800-1804, 2006.

[9] M. N. Bagde, A. K. Raina, A. K. Chakraborty, and J. L. Jethwa, "Rock mass characterization by fractal dimension," Engineering Geology, vol. 63, no. 1-2, pp. 141-155, 2002.

[10] G. Y. Wang, "Uncertainty information and its mathematical treatment," Journal of Harbin Architecture and Engineering Institute, vol. 23, no. 4, pp. 52-58, 1990.

[11] L. A. Zadeh, "Fuzzy sets," Information and Computation, vol. 8, pp. 338-353, 1965.

[12] G. Matheron, Random sets and integral geometry, John Wiley and Sons, New York, NY, USA, 1975.

[13] D. Ju-Long, “Control problems of grey systems," Systems \& Control Letters, vol. 1, no. 5, pp. 288-294, 1982.

[14] K. Liu, L. Yi, and L. Yao, "Informational uncertainties and their mathematical expressions," Kybernetes, vol. 30, no. 4, pp. 378396, 2001.

[15] K. Liu, Y. Lin, and L. Yao, "Unascertained rationals and subjective uncertain information," Systems Analysis Modelling 
Simulation. A Journal of Mathematical Modelling and Simulation in Systems Analysis, vol. 42, no. 3, pp. 343-357, 2002.

[16] C. Wen, T. A. Parsons, and B. Al Malik, "Unascertained Measurement Evaluation on Maintenance Quality of Highway Pavement," in Proceedings of the First International Symposium on Transportation and Development Innovative Best Practices, pp. 228-233, Beijing, China.

[17] Z. Yao and L. Cui, "Mechanical structure design optimization by blind number theory: time-dependent reliability. World Academy of Science, Engineering and Technology," International Journal of Mechanical, Aerospace, Industrial, Mechatronic and Manufacturing Engineering, vol. 6, no. 2, pp. 536-539, 2012.

[18] J. Zhou and X. Li, "Integrating unascertained measurement and information entropy theory to assess blastability of rock mass," Journal of Central South University, vol. 19, no. 7, pp. 1953-1960, 2012.

[19] S. C. Li, J. Wu, Z. H. Xu, and L. P. Li, "Unascertained measure model of water and mud inrush risk evaluation in karst tunnels and its engineering application," KSCE Journal of Civil Engineering, vol. 21, no. 4, pp. 1170-1182, 2017.

[20] Z. Pawlak, "Rough sets," International Journal of Computer \& Information Science, vol. 11, no. 5, pp. 341-356, 1982.

[21] J. W. Grzymala-Busse, Managing Uncertainty in Expert Systems, Springer US, Boston, MA, 1991.

[22] Z. Pawlak, Rough Sets: Theoretical Aspects of Reasoning about Data, Springer, Dordrecht, Netherlands, 1991.

[23] T. Beaubouef and F. E. Petry, "Uncertainty modeling for database design using intuitionistic and rough set theory," Journal of Intelligent \& Fuzzy Systems: Applications in Engineering and Technology, vol. 20, no. 3, pp. 105-117, 2009.

[24] R. Yasdi, "Combining rough sets learning- and neural learningmethod to deal with uncertain and imprecise information," Neurocomputing, vol. 7, no. 1, pp. 61-84, 1995.

[25] Y. C. Wang, H. Y. Sun, Y. Q. Shang, and M. Zhu, "Classification of wall rock based on Delphi method and ideal point method," Chinese Journal of Geotechnical Engineering, vol. 32, no. 4, pp. 651-656, 2010.

[26] Y. C. Wang, X. H. Xu, Y. L. Liu, and L. J. Zhou, "Set pair analysis model in wall rock classification of highway tunnel," Journal of Harbin Institute of Technology, vol. 43, no. 4, pp. 114-119, 2011. 


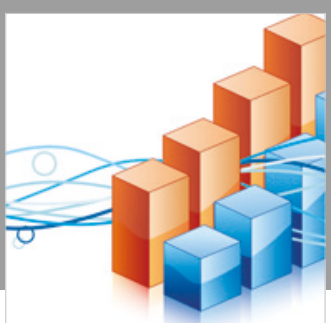

Advances in

Operations Research

\section{-n-m}
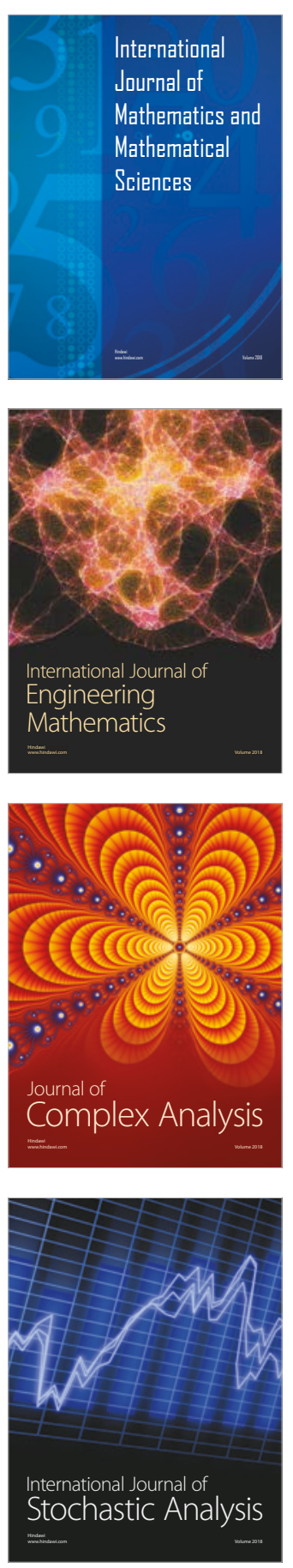
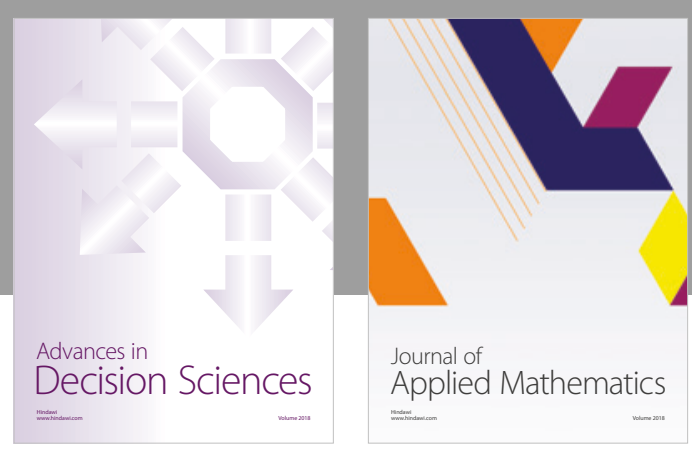

Journal of

Applied Mathematics
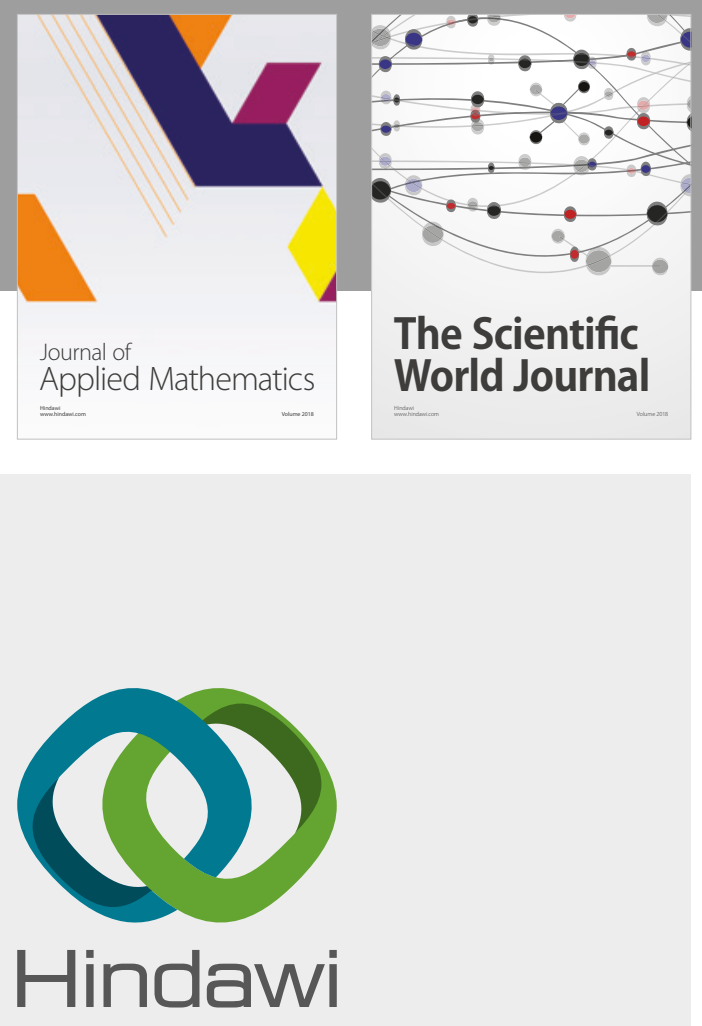

Submit your manuscripts at

www.hindawi.com

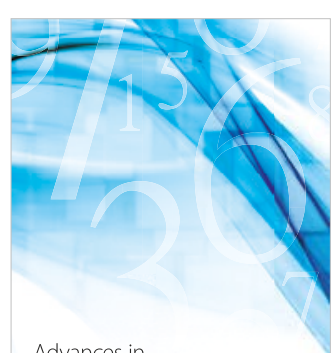

Advances in
Numerical Analysis
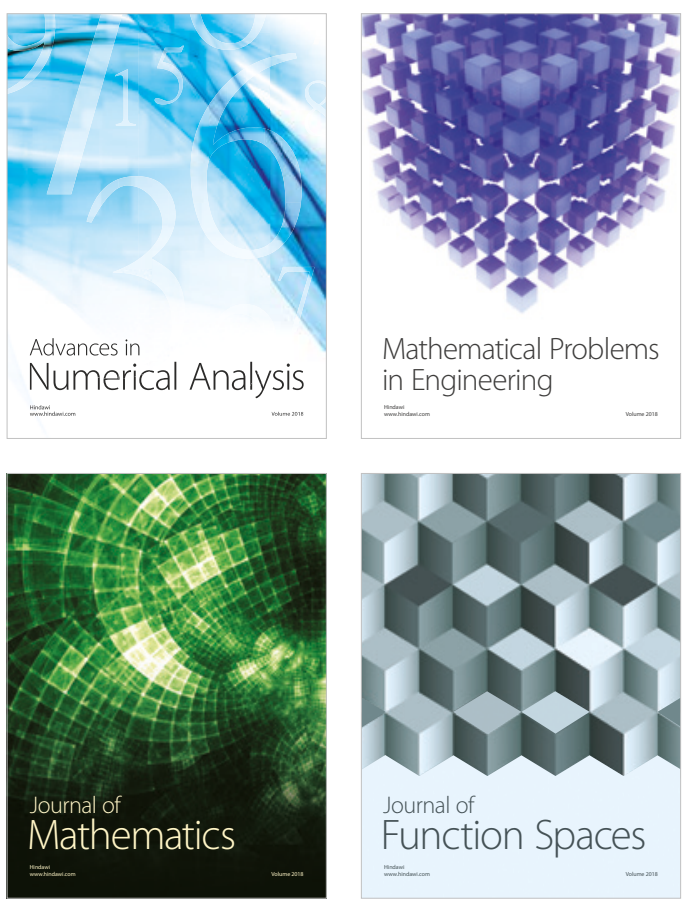

Mathematical Problems in Engineering

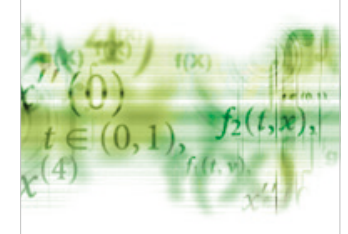

International Journal of

Differential Equations

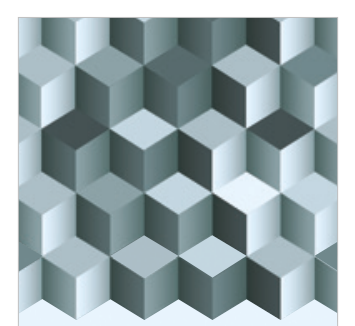

Journal of

Function Spaces

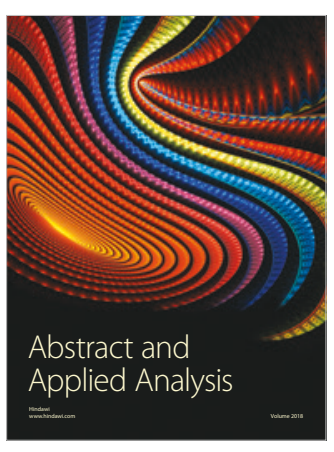

The Scientific

World Journal

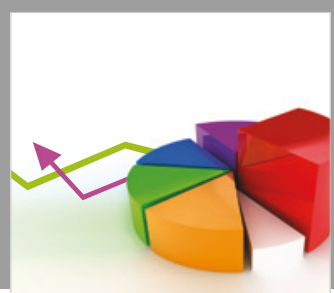

Journal of

Probability and Statistics
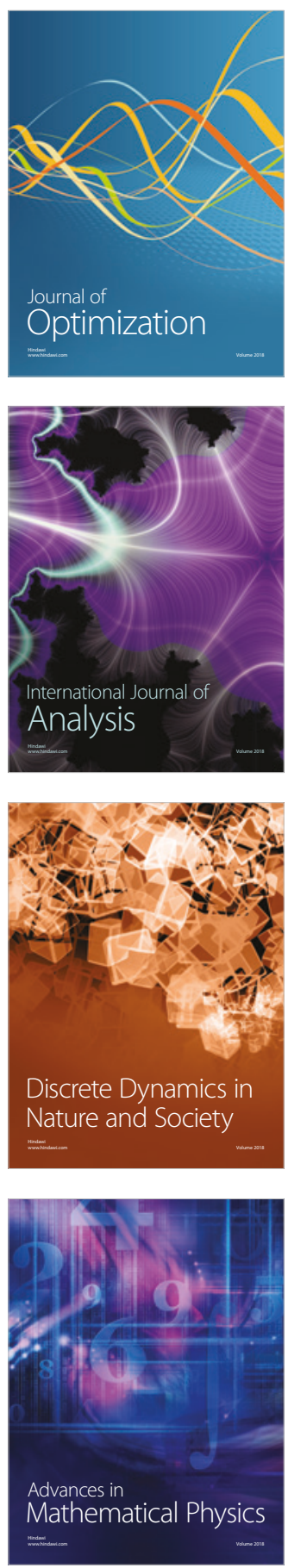